\title{
Kolonya ve El Dezenfektanlarının Alkolmetre Ölçümlerine Etkisinin Değerlendirilmesi
}

\section{The Evaluation of The Effect of Cologne And Hand Disinfectants on Alcohol Meter Measurements}

\author{
Kenan KAYA $^{1}$ (D) , Büşra DENiz ${ }^{1}$ \\ ${ }^{1}$ Çukurova Üniversitesi, Tıp Fakültesi, Adli Tıp Anabilim Dalı, Adana,TÜRKiYE
}

Öz.

Amaç: Bu çalışmada, pandemi sürecinde basılı ve çevrimiçi yayın organlarında çokça karşılaştığımız kolonya ve el dezenfektanı gibi maddelerin kullanımı sonrası hatalı alkolmetre ölçümlerinin yapıldığı haberler araştııılmıştır. Hatalı ölçüme neden olmakla suçlanan ürünler ve sonrasında yaşanan süreç üzerinden konuyu tartışmak amaçlanmıştır.

Materyal ve Metod: Tanımlayıcı tipte retrospektif bir çalışma olan bu araştırmada 2020 Ocak ile 2021 Mart ayları arasında yayınlanmış, internet aracılığı ile ulaşılabilen haberler incelenmiştir. Tarama sonucunda ulaşılabilen 20 haber örneklemimizi oluşturmuştur.

Bulgular: Alkolmetre ölçümlerinde yanlı̧s sonuca neden olmakla suçlanan ürünlerin \%40'ını $(n=8)$ kolonya ve el dezenfektanı, \%15'ini ( $n=3)$ ağız gargaraları oluşturmaktadır. Ölçümün hatalı veya yüksek olduğunu düşünen kişilerin \% $80^{\prime}$ ı itiraz amaçlı hastaneye başvurmuştur. Hastaneye başvuranların $\% 81,2{ }^{\prime}$ 'inde $(n=13)$ kandan bakılan alkol düzeyleri ' 0 promil' olarak bulunmuştur. Kolonya ve el dezenfektanı kullanan sürücülerin tamamı ölçüm yapılmadan kısa bir süre önce bu ürünleri dezenfeksiyon amaçlı ellerine ve yüzlerine sürdüklerini söylemişlerdir. Hatta bu sürücülerin bir kısmı, kendisinden önceki aracın kontrolünün yapıldığı sürede beklerken kolonya veya el dezenfektanı kullandıklarını ifade etmişlerdir.

Sonuç: Alkolmetre ile ölçüm yapılmadan önce, sonucu etkileyebileceği düşünülen ürünlerin yakın zamanda kullanımının gerçekleşip gerçekleşmediği sorgulanmalıdır. Gerekli görülen durumlarda sürücü bir süre bekletildikten sonra ölçüm yapılması, yanluş pozitif ölçüm sonuçlarılla karşılaşmamak adına faydalı olabilir.

Anahtar Kelimeler: Nefes Alkol testi, El dezenfektanı, Gazete, Haberler

Abstract

Background: In this study, the news of incorrect alcohol meter measurements were investigated after the use of substances such as cologne and hand sanitizer, which we encountered a lot in printed and online publications during the pandemic process. It is aimed to discuss the issue through the products accused of causing the incorrect measurement and the subsequent process.

Materials and Methods: In this research, which is a descriptive retrospective study, the news published between January 2020 and March 2021, which can be accessed via the internet, were examined. As a result of the scanning, 20 news that could be accessed formed our sample.

Results: Cologne and hand sanitizer constitute $40 \%(n=8)$ of the products accused of causing incorrect results in alcohol meter measurements and mouthwashes constitute $15 \%(n=3) .80 \%$ of people who think that the measurement is incorrect or high have applied to the hospital for objection purposes. In $81,25 \%$ ( $n=13)$ of those who applied to the hospital, blood alcohol levels were found to be '0 promile'. All of the drivers who used cologne and hand sanitizer said that they applied these products to their hands and faces for disinfection shortly before the measurement. Some of these drivers even stated that they used cologne or hand sanitizer while waiting during the time of control of the vehicle before them.

Conclusions: Before measuring with an alcohol meter, it should be questioned whether the recent use of products that are thought to affect the result has occurred. If necessary, it may be useful to take measurements after the driver has been waiting for a while so as not to encounter false positive measurement results.

Keywords: Alcohol breath test, Hand sanitizer, Newspaper, News

\section{Sorumlu Yazar / Corresponding Author}

Dr. Büşra DENiz

Çukurova Üniversitesi

Tıp Fakültesi

Balcalı Hastanesi,

Adli Tıp Anabilim Dalı,

Sarıçam, Adana, TÜRKIYE

E-mail: drbusradeniz@gmail.com

Geliş tarihi / Received: 13.08.2021

Kabul tarihi / Accepted: 05.11.2021

DOI: $10.35440 /$ hutfd. 982385 


\section{Giriş}

Illk olarak Aralık 2019'da Çin'in Wuhan eyaletinde görülen Koronavirüs (Covid-19) salgını kısa bir süre içinde dünyayı etkisi altına almıştır. Dünya Sağlık Örgütü (WHO) 11 Mart 2020'de Yeni Tip Koronavirüsü (Covid-19) pandemi olarak ilan etmiştir (1). Bu tarihte Türkiye'de de ilk Covid-19 vakası görülmüştür (2). Bu salgın tüm dünyada birçok konuda bireylerin yaşam tarzlarında, davranışlarında ve alışkanlıklarında değişikliklere neden olmuştur (3). WHO ve T.C Sağlık Bakanlığı'nın Covid-19 virüsünden korunmak için sıklıkla üzerinde durduğu en önemli önlem hijyendir. Ellerin sık sık yıkanması gerektiği vurgulanmıştır. Ayrıca hasta insandan yayılan damlacıkların temas edilen nesnelere de kolayca yerleşebildiği bilindiğinden; tüm yüzeylere ve eşyalara temas konusunda dikkatli olunması gerektiği belirtilmektedir $(1,2)$. Covid-19 salgını sürecinde temizlik maddelerine olan ilgi artmıştır. Özellikle çok miktarda satın alma ile ilgili yapılan çalışmalarda; kişisel bakım ve hijyen ürünleri ile temizlik malzemelerinde satışların arttığı belirtilmektedir $(4,5)$.

Anadolu Ajansının yaptığı bir haberde; Covid-19 virüsünden korunmak için sağlığı koruyan ekipman ve temizlik malzemelerine talebin arttığı, virüsün Türkiye'de görülmeye başladığı hafta, bir önceki haftaya göre kolonya satışının 34 kat, steril eldivenin 19 kat, el dezenfektanının 10 kat, sabunun 4 kat, medikal maskenin 4 kat, tuvalet kâğıdı satışının ise 3,5 kat arttığı belirtilmektedir (6). Google Trend verilerine göre ise salgının görülmeye başladığı zaman itibariyle kolonyaya gösterilen ilginin \%100'e ulaştığı görülmüştür (7).

Pandemi döneminde el hijyenini korumak amaçlı sık kullanılan kolonya ve alkol bazlı el dezenfektanlarının; trafik denetlemelerinde alkolmetre ile yapılan nefeste alkol ölçümlerinde hatalı sonuçlar vermeye neden olmakla suçlanmaları özellikle son zamanlarda gazete haberlerinde sıkça karşımıza çıkmaktadır. Bu konuda yapılan çalışmalarda nefes alkol testinde yanlış pozitif sonuca sebep olan bazı durumların olduğu, alkol bazlı el dezenfektanları, gargaralar, astım tedavisinde kullanılan inhaler ilaçlar, etanol içeren farmasötik preparatlar, ağız spreyleri, bazı kanser ilaçları ve homeopatik preparatların kullanımı sonrası nefes alkol düzeyinin pozitif çıkabileceği söylenmektedir (8-12). Etanol içerebilecek veya tüketimleri sonrası fermentasyon nedeniyle etanol oluşumuna neden olabilecek şalgam, şıra, kefir gibi gıda maddelerinin, enerji içeceklerinin, nefes tazeleyici tabletlerin ve nefeste alkol kokusuna neden olan bazı hastalıkların da nefes alkol testini etkileyebileceği düşünülmektedir $(13,14)$.

Alkolmetre ile yapılan ölçümlerin, nefeste alkol düzeyini etkileyebilecek ürünlerin kullanımı veya tüketilmesinden hemen sonra ya da ilk 15 dakika içinde yalancı pozitif sonuçlara neden olabileceği belirtilmektedir. Ölçümlerde bu duruma dikkat edilmesi, sonucu etkileyebileceği düşünülen ürünlerin kullanımı veya tüketiminin sorgulanması ve şüphe doğuran bir durum varsa en az 15 dakika beklendikten sonra ölçüm yapılması gerektiği vurgulanmaktadır (15). Çalışmamızın amacı, alkolmetre ile yapılan ölçümler sonrası görülebilecek yanlış pozitif sonuçlara dikkat çekmek, bu durumdan mağdur olduğunu ifade eden insanların izlediği yolları ve nasıl girişimlerde bulunduklarını ortaya koymaktır. Böylelikle mevcut problemin gündeme taşınmasının benzer mağduriyetlerin yaşanmaması için uygun çözümler getirilmesini sağlayabileceği ve bu konuda iyileştirmeler yapılabileceği düşünülmektedir.

\section{Materyal ve Metod}

Tanımlayıcı tipte retrospektif bir çalışma olan bu araştırmada basılı ve çevrimiçi yayın organlarında 2020 Ocak ayı ile 2021 Mart ayı arasında yayınlanan haberler incelenmiş, "trafik denetlemeleri, alkolmetre, hatalı alkol ölçümleri, koIonya ve dezenfektan kullanımının alkolmetreyi etkilemesi" anahtar kelimeleri girilerek alkolmetre ölçümlerine yapılan itirazlarla ilgili haberlere ulaşılmıştır. Tarama sonucunda alkolmetre ölçümlerine yapılan itirazlar ile ilgili ulaşılan 20 haber örneklemi oluşturmuştur.

Alkolmetre ölçümlerine yapılan itirazlar, habere konu olan kişilerin cinsiyeti, yaşı, nefesten alkol ölçümlerinde alkol düzeylerinin kaç promil çıktığı, hangi ürünlerin suçlandığı, suçlanan ürünleri kullandıktan veya tükettikten ne kadar süre sonra ölçüm yapıldığı, alkolmetrede saptanan pozitif ölçümün hatalı veya yüksek olduğunu düşünenlerin itiraz amaçlı hastane başvurusu olup olmadığı, hastane başvurusu olduysa kan alkol düzeyinin kaç promil çıktığı, ölçümlerin hangi günlerde yapıldığı, ölçümlerin gündüz saatinde mi, gece saatinde mi (00:00'dan sonra) yapıldığı başlıkları altında incelenerek analiz edilmiştir.

\section{Bulgular}

2020 Ocak ayı ile 2021 Mart ayı arasında yayınlanmış olan, çalışma kapsamında analiz edilen 20 haberden $18^{\prime}$ inde olguların sosyodemografik bilgilerine ulaşılabilmiş olup, bu kişilerin tamamının erkek cinsiyette ve yaşlarının 26 ile 74 aralığında olduğu görülmüştür.

Alkolmetre ölçümlerinde yanlış sonuca neden olmakla suçlanan ürünlerin \%40'ını ( $n=8)$, kolonya ve el dezenfektanlarının, \%15'ini ( $n=3)$ ise ağız gargaralarının oluşturduğu tespit edilmiştir. Bir kişinin ölçüm yapılmadan önce portakal yediğini, bir kişinin ise yemek yerken içtiği meyve suyu nedeniyle sonucun pozitif çıkmış olabileceğini, alkol kullanmadığını ifade ettiği görülmüştür. İtiraz edilen alkolmetre ölçüm sonuçlarında yanlış sonuca neden olmakla suçlanan ürünler Tablo 1'de gösterilmiştir.

İtiraza konu olan nefes alkol düzeyi ölçümlerinde en yüksek promil değeri 2,28 promil ve suçlanan ürün kolonya iken en düşük ölçüm değeri 0,26 promil ve bu ölçümde suçlanan ürün el dezenfektanıdır. 
Gargara kullanımının suçlandığı haberlerin incelemesinde ise ölçülen promil değerlerinin yasal sınır olan 0,5 promilin üzerinde olduğu dikkat çekmektedir (Tablo 2).

Tablo 1. İtiraz edilen ölçümlerde suçlanan ürünler

\begin{tabular}{lcc}
\hline Suçlanan Ürün & Sayı $(\mathbf{n})$ & Oran \\
\hline Kolonya & 5 & $\% 25$ \\
El dezenfektanı & 3 & $\% 15$ \\
Ağız gargarası & 3 & $\% 15$ \\
Portakal ve Meyve Suyu & 2 & $\% 10$ \\
Suçlanan ürün yok* & 7 & $\% 35$ \\
\hline
\end{tabular}

*Kişiler alkolmetre ile ölçülen alkol düzeylerine itiraz etmiş ve alkol kullanmadıklarını ifade etmişlerdir ancak sonucun hatalı çıkmasına neden olduğunu düşündükleri bir üründen bahsetmemişlerdir.

Tablo 2. Suçlanan ürünler, nefes ve kan alkol düzeyleri

\begin{tabular}{lcl}
\hline & Nefes & \\
Suçlanan Ürün & Alkol Düzeyi & Kan Alkol Düzeyi \\
\hline Kolonya & 0,62 promil & 0 promil \\
Kolonya & 0,42 promil & Hastane başvurusu yok \\
Kolonya & 0,56 promil & Hastane başvurusu yok \\
Kolonya & 0,27 promil & 0 promil \\
El Dezenfektanı & 2,28 promil & 0 promil \\
El Dezenfektanı & 0,30 promil & 0 promil \\
El Dezenfektanı & 0,35 promil & Hastane başvurusu yok \\
Gargara & 1,34 promil & 0 promil \\
Gargara & 2,0 promil & 0 promil \\
Gargara & 1,44 promil & 0 promil \\
Portakal & 0,56 promil & 0 promil \\
Meyve Suyu & 0,59 promil & 0 promil \\
\hline
\end{tabular}

Alkolmetrede saptanan pozitif ölçümün hatalı veya yüksek olduğunu düşünerek itiraz amaçlı hastaneye başvuran kişilerin örneklemin \%80'ını oluşturduğu görülmüştür. Bu kişilerin $\% 81,25$ 'inde $(n=13)$ kan alkol düzeyinin '0 promil' saptandığı, $\% 18,75$ 'inde $(n=3)$ ise kan alkol düzeyinin 0,3 promil altında ölçüldüğü belirtilmektedir. Bu ölçümler ile nefesten ölçülen alkol düzeyleri arasında anlamlı farklar bulunmaktadır (Tablo 3).

Tablo 3. Alkolmetre ölçüm sonuçlarına itiraz amaçlı hastaneye başvuran kişilerin kan alkol düzeyleri

\begin{tabular}{lll}
\hline Hastane Başvurusu/Kan Alkol Düzeyi & Sayı (n) & Oran \\
\hline Hastane başvurusu olan & 16 & $\% 80$ \\
Hastane başvurusu olmayan & 4 & $\% 20$ \\
Kan alkol düzeyi 0 promil çıkan & 13 & $\% 81,25$ \\
Kan alkol düzeyi <0,3 promil çıkan & 3 & $\% 18,75$ \\
\hline
\end{tabular}

Kolonya ve el dezenfektanı kullanan sürücülerin tamamı ölçüm yapılmadan kısa bir süre önce bu ürünleri dezenfeksiyon amaçlı ellerine ve yüzlerine sürdüklerini, hatta bir kısmı kendisinden önceki aracın kontrolü yapılırken beklediği sırada kolonya veya el dezenfektanı kullandıklarını ifade etmişlerdir.

İncelenen haberlerin 18 'inde alkolmetre ölçümlerinin yapıldığı gün bilgisine ulaşılabilmiş olup, bu ölçümlerin $\% 66,66$ 'sının ( $n=12)$ hafta içi günlerinde, \%33,33'ünün ( $n=6)$ hafta sonu günlerinde yapıldığı görülmüştür.

Ölçümlerin yapıldığı saat (gece/gündüz) bilgisine 14 haberde ulaşılabilmiştir. Ölçümlerin \%57,14'ünün $(n=8)$ gece saatlerinde, $\% 42,85^{\prime}$ inin $(n=6)$ ise gündüz saatlerinde yapıldığı tespit edilmiştir.

Yapılan ölçümlere ve verilen cezalara itiraz eden sürücüler kan alkol düzeylerinin tespiti için hastanelere yönlendirilmiş ve alkollü olmadıklarını kan alkol düzeyleri ile ispat etmiş olsalar da bu durum nefes alkol düzeyi ölçümü sonrası ceza yazılmasına engel olmamıştır. Alkolmetre ile yapılan ölçüm sonucuna itiraz eden sürücüler verilen cezaların iptali için mahkemeler aracılığıyla itiraz yoluna gitmişlerdir.

\section{Tartışma}

Sağlığın birçok alanında kullanılan testlerin ve tarama cihazlarının günümüz teknolojisinde bile $\% 100$ güvenilirliği ve özgüllüğü olmadığı gibi alkol taramalarında kullanılan ölçüm cihazlarının da yanlış negatif veya pozitif sonuçlar vermesi kaçınılmazdır. Bu cihazlarla yapılan ölçümlerde yanlış pozitif sonuçların alınmasının kişilere çeşitli yaptırımları ve Türk Ceza Kanunu hükümlerine göre cezaları vardır. Bu nedenle trafik denetlemelerinde yapılan tarama testleri ile elde edilen pozitif sonuçların gerekli görüldüğü hallerde ikinci kez ölçüm yapılarak veya farklı ölçüm methodlarıyla teyit edilmesi gerekmektedir (16). Adli açıdan ceza muhakemesine delil olabilecek bir alkolmetre ölçümünün en az 10 dakika beklendikten sonra tekrarlanması gerektiği belirtilmektedir (17).

Kişinin alkol kullanmadığı halde nefesten ölçülen alkol düzeyinin pozitif çıkması alkolmetre yanlış pozitif ölçümleri olarak karşımıza çıkmaktadır. Literatür taramasından anlaşıldığı üzere nefesten alkol düzeyi ölçümlerinde yaşanan yanlış pozitifliklerin; gastroözofageal reflü, diyabet gibi hastalıklar ve yüksek karbonhidratlı yiyecekler tüketmek gibi temellerinin yanında kolonya, el dezenfektanı, gargara, kişisel bakım ürünleri ve bazı farmasötik preparatların kullanımı, bazı besinler ve meyve sularının tüketimi sonrası da erken dönemde yanlış pozitif ölçümlere neden olabildiği belirtilmektedir $(18,19)$.

Bu çalışmada kolonya, el dezenfektanı veya gargara kullanımları sonrasında kısa bir süre içerisinde ölçüm yapıldığını ifade eden kişilerde alkolmetre ölçümlerinin yanlış pozitif sonuçlar verdiği görülmüştür.

2019 yılında Karabulut ve ark. yaptığı bir çalışmada iki farklı marka gargara, ağız spreyi ve tıraş kolonyasını 30 sağlıklı gönüllüye kullandırmış ve sonrasında yapılan nefes alkol düzeyi ölçümlerinin 0,5 promil üzerinde olduğunu bildirilmişlerdir (20). İtalya'da Foglio Bonda ve arkadaşları tarafından yapılan bir çalışmada ise gönüllü kişilerin alkol içerdiği bili- 
nen gargaraların kullanımı sonrası nefesten alkol düzeylerinin ölçüldüğü, 10. dakikada yapılan ölçümlerin sıfırıncı dakikada yapılana göre anlamlı derecede farklı olduğu belirtilmektedir (21). Modell ve ark. yaptıkları bir çalışmada, alkolmetrede yanlış pozitif ölçümlere en sık ağız bakım ürünlerinin neden olduğunu bildirmişlerdir (22). Bizim araştırmamızda kolonya ve el dezenfektanının sayıca ağız bakım ürünlerinden yüksek çıkmasının nedeninin pandemi döneminde olmamız ve el hijyenini sağlama amaçlı bu ürünlerin bu dönemde sık kullanılması kaynaklı olduğunu düşünmekteyiz.

Alkolmetre cihazı ile yapılan ölçümün; usulüne uygun yapılmadığı, iki defa tekrarlanmadığı veya ölçümü yapan aletin kalibrasyonunun iyi olmadığı durumlarda hatalı ölçümler yapabileceği söylenmektedir. Yapılan çalışmalarda yüze kolonya sürülmesiyle 1-2 dakika içinde cihazın 0,20-0,30 promil (\%20-30 mg) alkol gösterdiği, 3-4 dakika içinde etkisinin kaybolduğu, \%70'lik alkolle ağız çalkalandığında yaklaşık 15 dakika içinde etkisinin kaybolduğu, deodorant ve spreylerin cihazları en çok 1 dakika ve düşük oranlarda etkilediğinin görüldüğü belirtilmektedir (17).

Bilimsel çalışmalarda, alkole toleransın ve metabolize etme süresinin kişiler arasında farklılık gösterebileceği, aynı kişide farklı zamanlarda dahi değişebileceği, kişinin yaşı, kilosu, cinsiyeti, metabolizma hızı gibi pek çok faktöre bağlı olarak vücuttaki alkolün elimine edilme hızının değişebileceği belirtilmektedir. Adli tıp uygulamalarında kan alkol düzeyinin bir saatte ortalama $15 \mathrm{mg} / \mathrm{dl}$ (0,15 promil) azaldığı kabul edilmektedir. Ölçümlerde zamanın öneminin bazen gözden kaçtığı, bu sebeple ölçüm zamanının sağııklı kaydedildiğinin teyidinin gerektiği görülmektedir.

Alkolün solunum havası ile atılma hızı ve kandaki alkol yüzdesi ilişkisinden yola çıkılarak oluşturulan alkolmetrelerde; ağızda alkol bulaşıklığı olması ya da alkol alımını takiben ilk 15 dakika içerisinde (bazı kaynaklarda 25-45 dk) ölçüm yapılması durumunda, solunum havasındaki alkolün kan alkolünden yüksek yanlış çıkabildiği, ayrıca ölçümlerin güvenliği açısından ölçümde kullanılan cihazların bakımı ve kalibrasyonunun düzenli yapılması gerektiği dikkat edilmesi gereken hususlardır.

Araştırmamızda alkolmetre ölçümlerine yapılan itirazlara ilişkin gazete haberleri saptanmış ve incelenmiştir. Evreni 15 ay olan bu araştırmada yalnızca 20 haberin bulunması, belirlenen tarih aralığında alkometre ölçümlerine yapılan itirazların yalnızca 20 adet olduğu anlamına gelmemektedir. Resmi kurum ya da kuruluşlar tarafından alkolmetre ile yapılan ölçümlerde hata veya ölçümlere yapılan itiraz oranını belirleyecek bir çalışmaya ulaşılamamıştır. Bu bağlamda örneklemimizin evrenin içerisinde ne kadar yer kapladığı hususunda yorum yapmak doğru olmayacaktır.

Bu çalışmada ölçüm sonuçlarına itiraz eden sürücülerin; kolonya, el dezenfektanı, gargara kullandıktan veya portakal/meyve suyu tükettikten kısa bir süre sonra ölçüm yapıldığını ifade etmeleri, hastane başvurusu olanların tamamının kan alkol düzeylerinin 0 promil saptanması, alkolmetre ile ölçüm yapılmadan önce sonucu etkileyecek şüpheli ürün kullanımının sorgulanması ve daha önce yapılan çalışmalarda belirtildiği üzere bu gibi durumlarda sürücünün en az 15 dakika bekletildikten sonra tekrar ölçüm yapılması gerektiğinin önemini ortaya koymaktadır.

Gazetelere konu olan alkolmetre ölçüm sonuçlarına itiraz davaları benzer sorunla karşılaşan insanları haklarını arama konusunda ve izleyeceği yol konusunda bilinçlendirmiştir. Incelenen haberlerde mağduriyet yaşayan kişilerin okuduğu veya izlediği haberlerde benzer olayları daha önce başkalarının da yaşadığını gördüğünü dile getirdiği, haberlerin bu konuda farkındalık yarattığı dikkat çekmiştir.

Alkolmetreler ve ölçüm sonuçları ile ilgili yapılan çalışmaların amacı; ülkemizde ve dünyada yaşanan olgular üzerinden alınan bilirkişi raporları ve yapılan araştırmalar ile olası yanIış pozitif sonuçların önüne geçebilmek, sistemde yaşanan aksaklıkların önlenmesine yardımcı olarak mevcut sistemi iyileştirmek ve adli makamlara yardımcı olmaktır (23).

\section{Sonuç}

Nefes alkol testinde pozitif sonuç saptanan ancak alkol almadığını ifade eden ve yapılan ölçüme itiraz eden sürücülerin, zaman kaybetmeden kan ve/veya idrar alkol düzeylerine bakılması ve nörolojik muayeneyi de kapsayan ayrıntılı tıbbi muayenesinin yapılması için en yakın hastaneye yönlendirilmesi gerekmektedir. Bu alanda yaşanan problemlerin daha çok gündeme getirilmesi ve konu üzerinde daha geniş kapsamda çalışmalar yapılması, yaşanacak mağduriyetlerin önüne geçilmesi için uygun çözümler üretilmesine fayda sağlayacaktır.

\section{Çalışmanın Kısıtlılıkları}

Ulaşılabilen bilgi ve belgeler sınırlı olduğu için olguların tamamının yaş, cinsiyet gibi sosyodemografik özellikleri, alkolmetre ölçümlerinde yanlış pozitif sonuca neden olmakla suçlanan ürünlerin neler oldukları, alkolmetre ile ölçüm yapıldıktan ne kadar süre sonra hastaneye başvurdukları gibi ayrıntıların bir kısmına ulaşılamamıştır. Örneklemin sınırlı olduğu bu çalışmada tüm olguların istenen verilerine ulaşılamaması ve gazete haberlerine yansımayan olguların da değerlendirmeye alınmamış olması çalışmanın kısıtlılıklarındandır.

Etik onam: Çalışmamız gazete haberlerine yansıyan olgular üzerinden değerlendirilme yapılan bir araştırma makalesi olduğu için etik kurul onay belgesine ihtiyaç duyulmamıştır

\section{Yazar Katkıları:}

Konsept: K.K.

Literatür Tarama: K.K., B.D.

Tasarım: K.K., B.D.

Veri toplama: K.K., B.D.

Analiz ve yorum: K.K., B.D.

Makale yazımı: B.D.

Eleştirel incelenmesi: K.K., B.D.

Çıkar Çatışması: Yok

Finansal Destek: Yok 


\section{Kaynaklar}

1. World Health Organization. (2020). Coronavirus disease 2019 (COVID-19): situation report, 51. World Health Organization. https://apps.who.int/iris/handle/10665/331475.

2. T.C. Sağlık Bakanlığı COVID-19 (SARS-COV-2 Enfeksiyonu) Genel Bilgiler, Epidemiyoloji ve Tanı Rehberi. https://covid19.saglik.gov.tr/TR-66337/genel-bilgiler-epidemiyolojive-tani.html.

3. Çiçek B, Şahin H, Erkal S. "Covid-19 Hijyen Ölçeği": Bir Ölçek Geliştirme Çalışması. Turkish Studies. 2020;15(6):339350. https://dx.doi.org/10.7827/TurkishStudies.45906.

4. Yavuz F. Tarıma Koronavirüs Etkisi. Kriter. Aylık Siyaset Toplum ve ekonomi Dergisi. 2020;5(46):86-89.

5. Torun Kayabaşı E. Covid-19'un Piyasalara ve Tüketici Davranışlarına Etkisi. Avrasya Sosyal ve Ekonomi Araştırmaları Dergisi. 2020;7(5):15-25. ISSN:2148-9963.

6. Günyol A. Koronavirüs ile birlikte Türkiye'de e-ticaret satışları arttı. 2020. https://www.aa.com.tr/tr/ekonomi/koronavirus-ile-birlikte-turkiyede-e-ticaret-satislari-artti/1772734.

7. Güven H. Covid-19 Sürecinde E-Ticaret Sitelerine Yöneltilen Müşteri Şikâyetlerinin İncelenmesi. Turkish Studies. 2020;15(4):511-530. https://dx.doi.org/10.7827/TurkishStudies.44354

8. Hautemaniere A, Cunat L, Ahmed-Lechehebb D, Hajjard F, Gerardind F, Morele $Y$ et al. Assessment of exposure to ethanol vapors released during use of alcohol-based hand rubs by healthcare workers. J Infect Public Health. 2013;6(1):16-26.

https://doi.org/10.1016/j.jiph.2012.09.015

9. Gomez HF, Moore L, McKinney P, Phillips S, Guven H, Brent J. Elevation of breath ethanol measurements by metereddose inhalers. Ann Emerg Med. 1995;25(5):608-11. https://doi.org/10.1016/s0196-0644(95)70172-9

10. Boatto G, Trignano C, Burrai L, Spanu A, Nieddu M. Effects of homeopathic mother tinctures on breath alcohol testing. J Forensic Sci. 2015;60:231-233. https://doi.org/10.1111/1556-4029.12662.

11. Fries $\mathrm{H}$, Hitzschke $\mathrm{M}$, Lordicka $F$. A different kind of relapse: Ethanol as an additive in chemotherapy formulations. Oncol Res Treat 2019;42:350-353. https://doi.org/10.1159/000497216.

12. Haq MW, Batool M, Ahsan SH, Qureshi NR. Alcohol use in mouthwash and possible oral health concerns. J Pak Med Assoc. 2009;59(3):186-90. PMID:19288954.

13. Tümer $A R$, Lale $A$, Gürler $M$, Yıldırım MŞ, Kaynak AD, Akçan $R$. The effects of traditional fermented beverages on ethanol, ethyl glucuronide and ethyl sulphate levels. Egypt J Forensic Sci. 2018;8:33. https://doi.org/10.1186/s41935018-0064-8.

14. Hossain M, Jahan I, Akter S, Hasan M, Uddin K, Shawan M et al. Ethanol content in different energy drinks available in Bangladesh. Jahangirnagar University Journal of Biological Sciences. 2017;5(2):57-60. https://doi.org/10.3329/jujbs.v5i2.32531.

15. Ignacio-García JM, Ignacio-García JM, Almenara-Barrios J, Chocrón-Giraldez MJ, Hita-Iglesias C. A comparison of standard inhalers for asthma with and without alcohol as the propellant on the measurement of alcohol in breath. Journal of Aerosol Medicine.2005;18(2):193-197. https://doi.org/10.1089/jam.2005.18.193.
16. Aşırdizer M, Hekimoğlu Y. Trafikte Yol Kenarı Alkol, Uyuşturucu ve Uyarıcı Tarama Testleri: Tarihçesi, Gelişimi ve Günümüzde Kullanımı. Adli Tıp Bülteni. 2015;20(3):181187. https://doi.org/10.17986/blm.2015314267.

17. Türk Ceza Yasasına Göre Alkollü Araç Kullanmanın Güvenli Sürüş Yeteneğine Etkileri Çalıştay Sonuç Bildirgesi, Adli Bilimler Dergisi. 2009;8(4). http://www.turkhukuksitesi.com/makale_1159.htm.

18. Baduroğlu E, Durak D. Alkol ile İlgili Adli Tıp Sorunları. Uludağ Üniversitesi Tıp Fakültesi Dergisi. 2010;36(2):65-71. https://dergipark.org.tr/tr/download/article-file/420944

19. Uysal C: Solunum Havasında Alkol Düzeyini Etkileyen Etmenler: Uzmanlık Tezi, İstanbul: Marmara Üniversitesi Tıp Fakültesi Dahili Tıp Bilimleri Bölümü, 2009.

20. Karabulut $D$, Özbunar E, Aydoğdu M, Akgür S. Kişisel Bakım Ürünlerinin Kullanımı Sonrası Nefeste Alkol Saptanması. Adli Bilimler ve Suç Araştırmaları Dergisi. 2019;1(1):22-35. ISSN: 2687-3397.

21. Foglio-Bonda PL, Poggia F, Foglio-Bonda A, Mantovani $C$, Pattarino F, Giglietta A. Determination of breath alcohol value after using mouthwashes containing ethanol in healthy young adults. Eur Rev Med Pharmacol Sci. 2015;19(14):2562-6. https://www.europeanreview.org/article/9223.

22. Modell JG, Taylor JP, Lee JY. Breath Alcohol Values Following Mouthwash Use. JAMA. 1993;270(24),2955-6. https://doi.org/10.1001/jama.1993.03510240067034

23. Dağıığlu N. İnsan Performans/Davranış Toksikolojisi, Trafikte Alkol ve Madde Kullanımı. Akgür SA, Dağlıoğlu N, ed. Temel Adli Toksikoloji, 1. Baskı, Akademisyen Kitabevi, Ankara, 2018:25-44. 